Original Research Article

\title{
To evaluate efficacy of FNAC in diagnosis of cystic lesions in paediatric age group patients- $A$ retrospective study in a tertiary care teaching hospital
}

\author{
Nichlani R. ${ }^{1}$, Rohira N. ${ }^{2}$, Verma R. ${ }^{3}$, Verma $\mathbf{N}^{4}$, \\ ${ }^{1}$ Dr. Rashmi Nichlani, ${ }^{2}$ Dr. Nitin Rohira, both authors are affiliated with Department of Pathology, Chirayu Medical \\ College \& Hospital, Bhopal, India, ${ }^{3}$ Dr. Reena Verma, Department of Pharmacology, Chirayu Medical College \& \\ Hospital, Bhopal, India, ${ }^{4}$ Dr. Nitin Verma, Consultant Neonatologist and Pediatrician, Anushree Hospital, Bhopal.
}

Corresponding Author: Dr. Nitin Rohira, Department of Pathology, Chirayu Medical College \& Hospital, Bhopal, India, Email: drrashminichlani@gmail.com

\begin{abstract}
Introduction: Fine Needle Aspiration Cytology is a rapidand economical mode of preoperative diagnosis. It has early availability of results \& simple procedure with minimal trauma and complications but it has limited literature in pediatric age group and cystic lesions with and remains an area which needs more light. Objective: To evaluate the role of fine needle aspiration cytology as a diagnostic tool for cystic lesions in paediatric patients of age up to 12 years. Methods: A retrospective study was undertaken toevaluate efficacy of FNAC in diagnosis of cystic lesions in paediatric age group patients of age upto 12 years presenting in the department of pathology of a tertiary care teaching hospital. Case sheets for 2 years study duration were studied and analysed for data. Common age group, male: Female, commonest site, commonest diagnosis as benign \& malignant lesion were study parameters along with positive predictive value, sensitivity \& specificity. Results: 105 cases were reported in a period of 2 years, out of which 17.14\% were reported from age group 01 month-04 years, $58.09 \%$ in $04-08$ years \& rest $24.76 \%$ were reported in $08-12$ years age group. $60.95 \%$ of patients were female. Commonest site was head \& neck $(86.66 \%)$ followed by abdomen $(5.71 \%)$, extremities $(3.80 \%)$ chest \& pelvis $(1.90 \%$ each). Commonest diagnosis was chronic inflammatory cysts $(32.38 \%)$, followed by benign cysts $(27.6 \%)$, acute inflammatory lesions $(15.23 \%)$ acquired cysts $(12.38 \%)$, developmental cysts $(10.47 \%) \&$ malignant cysts in $1.90 \%$. Conclusion: FNAC is an efficacious diagnostic tool with high sensitivity \& specificity and minimal safety concerns.It is showing to be equally promising in diagnosis of cystic lesions in paediatric age.
\end{abstract}

Keywords: FNAC, Paediatric, Cystic lesion

\section{Introduction}

Fine Needle Aspiration Cytology (FNAC) is a rapid, convenient and economical mode of preoperative diagnosis. There are many studies in adult age groups but due to limited literature in pediatric age group, small study samples sizes \& varying results, it remains the area which needs more light. Fine needle aspiration cytology (FNAC) is frequently being used for the diagnosis of salivary gland and neck swellings, and thyroid masses.

It is the diagnostic technique which has early availability of results $\&$ simple procedurewith minimal trauma and complications. The cytomor-phological features collaborate with the histopathology \& has the qualities of a micro-biopsy $[1,2]$.

Manuscript received: $30^{\text {th }}$ July 2018 Reviewed: $7^{\text {th }}$ August 2018

Author Corrected: $14^{\text {th }}$ August 2018

Accepted for Publication: $18^{\text {th }}$ August 2018
Along with rapid diagnosis, if necessary, a re-aspiration can be done quickly at the time of initial testing [3]. However, this technique is still not widely accepted for use in pediatric patients due to the unknown sensitivity of this modality and lack of experienced cytopathologists who are familiar with pediatric cytology smears [4,5]. But this safe, reliable, cost-effective and easy procedure can eliminate the need for open biopsy procedure, with its potential untoward effects $[1,6]$.

Ancillary techniques such as flow cytometry, cytogenetics, electron microscopy and cell block preparations with immunocytochemistry can be applied for the characterization of tumours. In addition, their benefits include the lack of sedation or general anaesthesia [7]. Previous reports have suggested its utility in only a small series of pediatric populations. Only few studies which were done on children, FNAC 


\section{Original Research Article}

have focused exclusively on both the benign and malignant lesions that occur in the regions of the head and neck. FNAC of the head and neck region is a generally well-accepted technique that has high specificity $[5,8,9]$. By providing few false-negative diagnosis, the categorization of the lesions into inflammatory / benign and malignant is possible, with a high degree of certainty [10].

With the increasing costs of medical facilities, any technique which speeds up the process of the diagnosis and limits the physical/psychological trauma to the patients, will be of tremendous value. FNAC helps the surgeons in selecting, guiding and modifying the surgical planning in patients who require surgeries or a general clinical management such as the need of an antibiotic treatment and or a neoadjuvent chemotherapy [8].

Cysts and associated lesions with cystic changes are commonly encountered in the head and neck region. Pathology of these lesions is diverse and includes developmental, inflammatory, benign tumours and malignant tumours which could be primary or metastatic. In children majority of the cysts are benign, whilst in adults, an asymptomatic neck cyst usually implicates malignancy. It is therefore essential to obtain an accurate pre-operative diagnosis for appropriate patient management.

FNAC is a well established tool in the head and neck lesions. However, its usefulness in the cystic lesions has been evaluated in a limited number of studies, the major pitfall being low cellularity, reactive atypia and cellular degeneration [11] [12]. Although, radiology helps to narrow down the differential diagnosis in cysts and lesions associated with cystic changes, an open surgical biopsy remains the gold standard, thus adding burden to the patient care [12]. The present study was designed to study the role of fine needle aspiration cytology and its utility in paediatric head and neck lesions. It also specifies the spectra of the head and neck lesions in the paediatric age group and correlates the cytomorphological features with the histomorphological findings, whenever they are available. The aim of the study was to evaluate the usefulness of FNAC in primary investigation of the considerable spectrum of cystic lesions that occurred in the head and neck region in a developing country like ours.

\section{Methodology}

Ethics: Institutional Ethics Committee approval was obtained prior to conduct of the study.

Study type: It was a retrospective observational study

Study site: The study was conducted in the department of pathology of a tertiary care teaching hospital in India.

Study duration: The study duration was of two years from January 2016 to January 2018.

Inclusion criteria: The study included 105 cases ofchildren of up to 12 years of age presenting with cystic lesions

Exclusion criteria: All solid lumps were excluded from the study.

Study conduct: A retrospective study was undertaken to evaluate efficacy of FNAC in diagnosis of cystic lesions in paediatric age group patients of age up to 12 years presenting in the department of pathology of a tertiary care teaching hospital. Case sheets for 2 years study duration were studied and analysed for data. Common age group, male: Female, commonest site, commonest diagnosis as benign \&malignant lesion were study parameters along with positive predictive value, sensitivity \& specificity.

Sample size: All cases with diagnosis of cystic lesions in paediatric age group patients of age up to 12 years presenting in the department of pathology were included in the study.

Statistical analysis: Descriptive analysis

\section{Results}

Commonest diagnosis Thyroglossal cyst (7.61\%), Mucocele retention (6.6\%), Lymphangioma (11.4\%), Hemangioma (15.2\%), Benign abdominal cysts (ovarian \& mesenteric 3 each) (5.71\%), Lymphoepithelial cysts (1.9\%), Dermoid (3.8\%), eosinophilic granuloma (1.9\%), acute inflammatory abscess $(15.2 \%)$, cold abscess $(30.4 \%)\{$ Table 4$\}$

Table-1: Age Distribution.

\begin{tabular}{|c|c|}
\hline Age groups & Percentage \\
\hline 1month to 4 years & 17.14 \\
\hline 4 years to 8 years & 58.09 \\
\hline 8 years to 12 years & 24.76 \\
\hline
\end{tabular}




\section{Original Research Article}

In the present study FNAC was performed on 105 cases that were reported in a period of 2 years out of which $17.14 \%$ were reported from age group 01 month-04 years, 24.76\% 08-12 years age group but the highest incidence was found in age group 04-08 years as $58.09 \%$.

Table-2: Gender distribution.

\begin{tabular}{|c|c|}
\hline Gender & Percentage \\
\hline Males & 39.05 \\
\hline Females & 60.95 \\
\hline
\end{tabular}

There is female predominance with $60.95 \%$ of patients as females. The

Table-3: Distribution according to site of lesion.

\begin{tabular}{|c|c|}
\hline Commonest sites & Percentage \\
\hline Head and neck & 86.66 \\
\hline Abdomen & 5.71 \\
\hline Extremities & 3.8 \\
\hline Chest & 1.9 \\
\hline Pelvis & 1.9 \\
\hline
\end{tabular}

Most common sitewas head \& neck (86.66\%) followed by abdomen (5.71\%), extremities $(3.80 \%)$ chest \& pelvis (1.90\% each).

Table-4: Distribution according to diagnosis.

\begin{tabular}{|c|c|}
\hline Diagnosis & Percentage \\
\hline Chronic Inflammatory cyst & 32.38 \\
\hline Benign cyst & 27.6 \\
\hline Acute inflammatory cyst & 15.23 \\
\hline Acquired cyst & 12.38 \\
\hline Developmental cyst & 10.47 \\
\hline Malignant cyst & 1.9 \\
\hline Eosinophilic granuloma & 1.9 \\
\hline Lymphoepithilial cysts & 1.9 \\
\hline Dermoid cyst & 3.8 \\
\hline Benign abdominal cyst & 5.71 \\
\hline Mucocele retention & 6.6 \\
\hline Thyroglossal cyst & 7.61 \\
\hline Lymphangioma & 11.40 \\
\hline Acute inflammatory abscess & 15.20 \\
\hline Hemangioma & 15.20 \\
\hline Cold abscess & 30.40 \\
\hline
\end{tabular}

\section{Discussion}

The swellings in the neck require a detailed clinicopathological evaluation because of the cosmetic aspect and the other being the possibility of the lesion being malignant. The lesion in the neck is visible to the patient and others and can be a source of constant worry to the patient and parents. For a clinician, a neck lesion could be a sign of deep seated pathology which nobody can afford to overlook [13].

There has been rise in interest of the use of FNAC as diagnostic tool in paediatric age group as reflected by increase in number of studies conducted. As such, most of the studies in paediatric age group have been for head \& neck region [14]. FNAC is popular diagnostic tool for superficial or deep masses in adults. Cystic lesions in paediatric age group are very commonranging from inflammatory, benign, congenital and malignant lesions $[15,16,17]$. 


\section{Original Research Article}

Though FNAC has become an established grown tool for solid lesions, but in paediatric cystic lesions very few studies were there the major drawback FNAC in cystic lesion were paucicellularity and to overcome this we added liquid based cytology in serous or watery fluid to increase the cellularity. In the present study highest incidence was found in age group $04-08$ years as $58.09 \%$. This was in contrast to findings of other studies like Maheshwari, et al[18] where majority of cases $(40.82 \%)$ were in the age group of 11-14 years, Shirian S et al were majority were in age group 15 to 18 years [38.5\%]. There was a female predominance with $60.95 \%$ of patients as females the male: female ratio being $0.64: 1$. This was in accordance with other studies where there was female preponderance (53.7\%), and in contrast to some studies with male predominance (males 60.46\%) [19, 20].

The most common site for the cystic lesions in the present study was head \& neck (86.66\%) and the commonest diagnosis reported was cold abscess (30.4\%). This was similar to results of previously conducted similar studies by M. Jain, et al \& Rapkiewicz, et al which reported $81 \%$ (head \& neck) \& 30\% (tubercular) respectively [7], [14]. In various studies higher incidence of unsatisfactory aspirates in the range of 9.3-15\% [17] [21] were reported. In our study the near patient FNAC was performed by the cytopathologist and was repeated in case of unsatisfactory aspirate, so it did not pose any problem with the diagnosis. Benign lesion were predominantly diagnosed which correspondent to that found in other studies $[14,22,23]$. Eosinophilic granuloma was reported only in $1.9 \%$ of cases.

The head and neck lesions in children are mostly benign in nature, with a small percentage of malignant lesions which usually present as head and neck masses. M. Jain, et al, Handa U, et al, Kim et al reported1.5, 1.54, 2.6\% of malignant lesions. Mittra et al, Sahni et al and other studies have reported very high incidence $11.83 \%, 20.98$ and $17 \%$ respectively in comparison and this may be due to thedifference in age composition of our study subjects $[4,7,8,11,20]$.

Commonest head and neck cystic lesions were benign congenital cysts and inflammatory lesions mainly hot and cold abscess, Z N Stain were shows positivity in $62 \%$ cases of cold abscess. Similarly, Sharrif et al reported the inflammatory lesions accounting for $64 \%$, followed by the congenital $20 \%$ [13]. In rest patients has already started AKT by some family physician without confirming the diagnosis. But in cold abscess FNAs, well-formed epithelioid granulomas may not be seen. Poorly formed granulomatous reaction may also be seen in HIV-positive patients affected by Mycobacterium avium-intracellulare. Diagnosis of such lesions based solely on FNA cytomorphologic features may be difficult. Differentiating tubercle bacilli from other mycobacteria such as $\mathrm{M}$ avium-intracellulare may be problematic unless cultures are used [24]. The various congenital neck swellings that we came across in our study are the dermoid cyst, thyroglossal cyst, branchial cyst. Some of the other congenital neck masses found in the pediatric population are vascular malformations, cystic hygroma, sebaceous cyst and hemangiomas. Congenital neck masses are excised to prevent potential growth and secondary infection of the lesion [13].

Incases of superadded acute inflammation masking the true nature, repeat near patient FNAC is advised after the course of antibiotic. Branchialcyst, keratinous cyst and dermoid cystall are common in children and FNAC of all three almost reveal same picture, i,easquames and, sometimes we get lymphoid tissue in branchialcyst, inflammation in keratinous cyst and hair shaft in dermoid, but majority of times the location decides final diagnosis along with FNAC finding more over the treatment of all three is simple excision so doesn'tmake big difference even if we cannot subtypedogmatically.

Limitation- Major limitation was small no of causes with surgical follow up, further studies with large no of surgical follow up is necessaryto strengthenour findings.

\section{Conclusions}

Cystic lesions in paediatric age group is almost $90 \%$ benign and FNAC is easy painless OPD procedure, so is a golden tool to make preoperative diagnosis in paediatric cystic lesion with high sensitivity and specificity good predicatic patient acceptance noted after surface Anaesthesia and lidocaine spray, FNAC can be repeated if needed and parents panic can be relieved on same day. So FNAC is a golden tool in paediatric cystic lesions.

Recommendations- Although diagnosis of cystic should be based on clinical history and physical examination to avoid excess complementary examinations, often not tolerated in this age group, biopsy is essential for definitive diagnosis and should be sought in cases of persistent and suspicious lesions, preferring to Fine-needle aspiration. In cases with superadded acute inflammation, repeat near patient FNAC after a course of antibiotic as inflammation can mask the truenature of the lesion. 


\section{Original Research Article}

\section{What this study adds to existing knowledge?}

There are many studies on use of FNAC in adult age groups but there is limited literature in pediatric age groups. Among the few studies which were done on children, the focus has been exclusively on both the benign and malignant lesions that occur in the regions of the head and neck. The present study includes all cystic lesions in paediatric ages without any focussed site specifications.

Contribution by authors.

\begin{tabular}{|c|c|c|c|c|}
\hline & Contributor 1 & Contributor 2 & Contributor 3 & Contributor 4 \\
\hline Concepts & + & & + & \\
\hline Design & & & & \\
\hline Definition of intellectual content & + & + & & + \\
\hline Literature search & & & & \\
\hline Clinical studies & + & & & \\
\hline Experimental studies & + & + & + & \\
\hline Data acquisition & + & & + & + \\
\hline Data analysis & & & + & + \\
\hline Statistical analysis & + & & & + \\
\hline Manuscript preparation & + & & & \\
\hline Manuscript editing & + & & & \\
\hline Manuscript review & + & & & + \\
\hline Guarantor & + & & & \\
\hline
\end{tabular}

Funding: Nil, Conflict of interest: None initiated Permission from IRB: Yes

\section{References}

1. Singh S, Garg N, Gupta S. Fine needle aspiration cytology in lesions of oral and maxillofacial region: Diagnostic pitfalls. J Cytol. 2011;28(3):93-7.

2. Steel BL, Schwartz MR, Ramzy I. Fine needle aspiration biopsy in the diagnosis of lymphadenopathy in 1,103 patients. Role, limitations and analysis of diagnostic pitfalls. Acta Cytol. 1995 Jan-Feb;39(1): 76-81.

3. Scher RL, Oostingh PE, Levine PA, et al. Role of fine needle aspiration in the diagnosis of lesions of the oral cavity, oropharynx, and nasopharynx. Cancer. 1988 Dec 15;62(12):2602-6.

4. Kim S, Jang EJ, Jeong JY, Park JY. Clinical usefulness of fine needle aspiration cytology in patients less than 20 years old: a 10-year experience at a single institution. Int J Clin Exp Pathol. 2013;6(12):2962-7.

5. Liu ES, Bernstein JM, Sculerati N, Wu HC. Fine needle aspiration biopsy of pediatric head and neck masses. Int J Pediatr Otorhinolaryngol. 2001 Aug 20;60 (2): $135-40$.
6. Günhan O, Doğan N, Celasun B, et al. Fine needle aspiration cytology of oral cavity and jaw bone lesions. A report of 102 cases. Acta Cytol. 1993 Mar-Apr;37 (2): 135-41.

7.Rapkiewicz A, Thuy Le B, Simsir A, et al. Spectrum of head and neck lesions diagnosed by fine-needle aspiration cytology in the pediatric population. Cancer. 2007 Aug 25;111(4):242-51.

8. Mittra P, Bharti R, Pandey MK. Role of fine needle aspiration cytology in head and neck lesions of paediatric age group. J Clin Diagn Res. 2013 Jun; 7 (6): 1055-8. doi: 10.7860/ JCDR/2013/ 5384. 3067. Epub 2013 May 15.

9. el Hag IA, Chiedozi LC, al Reyees FA, Kollur SM. Fine needle aspiration cytology of head and neck masses. Seven years' experience in a secondary care hospital. Acta Cytol. 2003 May-Jun;47 (3):387-92.

10. Boccato P, Altavilla G, Blandamura S. Fine needle aspiration biopsy of salivary gland lesions. A reappraisal of pitfalls and problems. Acta Cytol. 1998 Jul-Aug;42(4):888-98.DOI:10.1159/000331964 


\section{Original Research Article}

11. Sahni S, S VS, Krishnappa A. Diagnostic Efficacy of Fine Needle Aspiration Cytology in Cystic Lesions of Head and Neck Region - A single Experience at Tertiary Health Care Centre. Natl J Lab Med. 2017; 6 (2):1-7.

12. Firat P, Erso C, Ugu A OS. Cystic lesions of the head and neck: cytohistological correlation in 63 cases. Cytopathology. 2007;18(3):184-90.

13. Shariff MA. Etiopathological study of pediatric neck masses in a rural population. Int $\mathrm{J}$ Otorhinolaryngol Head Neck Surg. 2018;4(5):1206-11.

14. Jain M, Majumdar DD, Agarwal K, et al. FNAC as a diagnostic tool in pediatric head and neck lesions. Indian Pediatr. 1999 Sep;36(9):921-3.

15. Young JE, Archibald SD, Shier KJ. Needle aspiration cytologic biopsy in head and neck masses. Am J Surg. 1981 Oct;142(4):484-9.

16. Raju G, Kakar PK, Das DK, et al. Role of fine needle aspiration biopsy in head and neck tumours. $\mathrm{J}$ Laryngol Otol. 1988 Mar;102(3):248-51.

17. Smallman LA, Young JA, Oates J, et al. Fine needle aspiration cytology in the management ENT of patients. J Laryngol Otol. 1988 Oct;102(10):909-13.
18. Maheshwari V, Alam K, Jain A, Agarwal S CR. Diagnostic utility of fine needle aspiration cytology in pediatrictumors. J Cytol. 2008;25:45.

19. Shirian S, Daneshbod $\mathrm{Y}$, Haghpanah $\mathrm{S}$, et al. Spectrum of pediatric tumors diagnosed by fine-needle aspiration cytology. DOI:10.1097/MD. 000000000000 5480

20. Mohan A, Jain RK, Thakral RK. Cytomorphological spectrum of pediatric head and neck lesions - a comparative study in a tertiary teaching hospital in Western Uttar Pradesh, India. Indian J Pathol Oncol. 2016; 3(3):450-5.

21. Sismanis A, Strong MS, Merriam J. Fine needle aspiration biopsy diagnosis of neck masses. Otolaryngol Clin North Am. 1980;13(3):421-9.

22. Mobley DL, Wakely PE Jr, Frable MA. Fine-needle aspiration biopsy: application to pediatric head and neck masses. Laryngoscope. 1991 May;101(5):469-72.doi: 10. 1288/00005537-199105000-00004

23. Taylor SR NC. Fine needle aspiration biopsy in a paediatric population. Report of 64 consecutive cases. Cancer. 1984;54:1449-53.

24. Dilip K. Das. Fine-Needle Aspiration Cytology in the Diagnosis of Tuberculous Lesions. Lab Med. 2000; $31(11): 625-32$.

\section{How to cite this article?}

Nichlani R, Rohira N, Verma R, Verma N. To evaluate efficacy of FNAC in diagnosis of cystic lesions in paediatric age group patients- A retrospective study in a tertiary care teaching hospital. Trop J Path Micro 2018; 4(5):415-420.doi:10. 17511/jopm.2018.i05.08 